\title{
New Biology to New Treatment of Helicobacter pylori-Induced Gastric Cancer
}

\author{
Richard M. Peek Jr. \\ Division of Gastroenterology Department of Medicine, Vanderbilt University School of Medicine, \\ Nashville, Tenn., USA
}

\author{
Key Words \\ Bacterial secretion system · Cytokines · Diet · Gastric \\ adenocarcinoma $\cdot$ Helicobacter pylori
}

\begin{abstract}
Background: Helicobacter pylori is a bacterial carcinogen that is supposed to have the highest known level of risk for the development of gastric cancer, a disease that claims hundreds of thousands of lives per year. Approximately $89 \%$ of the global gastric cancer burden and $5.5 \%$ of malignancies worldwide are attributed to $H$. pylori-induced inflammation and injury. However, only a fraction of colonized persons ever develop neoplasia, and disease risk involves well-choreographed interactions between pathogen and host, which are dependent upon strain-specific bacterial factors, host genotypic traits, and/or environmental conditions. Key Messages: One $H$. pylori strain-specific virulence determinant that augments the risk for gastric cancer is the cag pathogenicity island, a secretion system that injects the bacterial oncoprotein CagA into host cells. Host polymorphisms within genes that regulate immunity and oncogenesis also heighten the risk for gastric cancer, in conjunction with $H$. pylori strain-specific constituents. Further, conditions such as iron deficiency and high salt intake can influence $H$. pylori phenotypes that lower the threshold for disease. Conclusions: Delineation of bacterial, host, and environmental mediators that augment gastric cancer risk has profound ramifications for both physicians and biomedical researchers as such findings will not only focus prevention approaches that target
\end{abstract}

H. pylori-infected human populations at increased risk for stomach cancer, but will also provide mechanistic insights into inflammatory carcinomas that develop beyond the gastric niche.

(c) 2016 S. Karger AG, Basel

\section{Introduction}

Helicobacter pylori is a bacterial carcinogen that is found to have the highest known level of risk for the development of gastric cancer. With an estimated 1 million new cases/year, gastric adenocarcinoma claims $>700,000$ lives each year and approximately $89 \%$ of the global gastric cancer burden and $5.5 \%$ of all malignancies worldwide are attributable to $H$. pylori-induced inflammation and injury [1].

Two histologically distinct forms of gastric adenocarcinoma have been well-defined, diffuse-type and intestinaltype, both of which are linked to $H$. pylori infection. Diffuse-type cancer is characterized by widespread neoplastic cell infiltration throughout the gastric mucosa, while intestinal-type cancer progresses through a series of well-defined pathological steps from normal gastric mucosa to superficial gastritis, chronic gastritis, atrophic gastritis, intestinal metaplasia, and finally dysplasia and adenocarcinoma (fig. 1) $[2,3]$. Chronic H. pylori infection induces gastric inflammation and thus increases the risk of progression through each of these well-defined steps of gastric transformation, including atrophic gastritis, intestinal metapla-

\section{KARGER}

E-Mail karger@karger.com

www.karger.com/ddi
(C) 2016 S. Karger AG, Basel

0257-2753/16/0345-0510\$39.50/0 


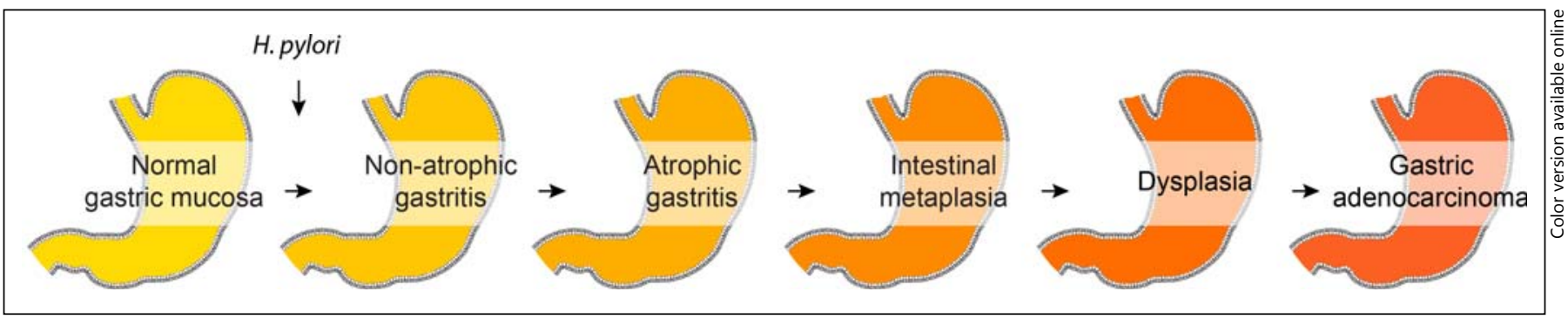

Fig. 1. Histologic cascade to intestinal-type gastric adenocarcinoma associated with $H$. pylori infection.

sia, and dysplasia, which are considered precursors to the development of gastric adenocarcinoma (fig. 1). In contrast to histologic stratification of gastric cancers, a recent study conducted comprehensive molecular analyses of gastric cancer cases to further classify gastric cancer into subtypes specifically associated with distinct clinical outcomes [4]. This classification yielded 4 subtypes, including MSI, TP53 ${ }^{+}$, TP53-, and EMT [4]. MSI or microsatelliteunstable tumors exhibited the best overall prognosis and the lowest frequency of recurrence [4]. The TP53 or tumor protein 53 classifications of active $\left(\mathrm{TP} 53^{+}\right)$or inactive $\left(\mathrm{TP}^{-} 3^{-}\right)$yielded intermediate prognosis and recurrence rates, with the inactive form yielding worse prognosis than the active form [4]. Finally, the EMT or epithelial-to-mesenchymal transition type classification exhibited the worst prognosis and the highest recurrence frequency [4]. These new molecular classifications of gastric cancer will likely improve future screening practices.

However, only a percentage of $H$. pylori-colonized persons ever develop neoplasia, and enhanced risk is related to bacterial strain differences, inflammatory responses governed by host genetic diversity, and/or specific interactions between host and microbial determinants [3]. These observations, in conjunction with evidence that carriage of certain strains is inversely related to esophageal adenocarcinoma and atopic diseases [3], underscore the importance of identifying mechanisms that regulate interactions of $H$. pylori with its host, which promote carcinogenesis.

\section{H. pylori Virulence Factors That Influence Gastric Cancer Risk}

H. pylori strains exhibit a high level of genetic diversity [5]. The cag pathogenicity island is a strain-specific locus that encodes a type IV secretion system (TFSS) [6] and $\mathrm{cag}^{+}$strains markedly augment the risk for gastric cancer

New Biology to New Treatment of

H. pylori-Induced Gastric Cancer compared to $\mathrm{Cag}^{-}$strains [7]. The product of the cagA gene (CagA) is translocated by the TFSS into epithelial cells, undergoes tyrosine phosphorylation [8-10], and activates a eukaryotic phosphatase (SHP-2), leading to cellular responses that may lower the threshold for transformation [8-10]. Our group and others have demonstrated that non-phosphorylated CagA also exerts pathologic effects including the activation of $\beta$-catenin, disruption of apicaljunctional complexes, and a loss of cellular polarity [1114], alterations that play a role in carcinogenesis. In addition to CagA, the cag TFSS delivers peptidoglycan into host cells where it is recognized by nucleotide-binding oligomerization domain 1, an intracytoplasmic sensor of bacterial peptidoglycan components [15]. Disruption of H. pylori peptidoglycan synthesis attenuates $\beta$-catenin activation, autophagy, and the development of pre-malignant lesions in response to $\mathrm{cag}^{+}$strains [16].

VacA, a toxin secreted by H. pylori, is another microbial constituent linked to the development of gastric cancer [17]. All $H$. pylori strains possess vacA, but there are considerable differences in $v a c A$ sequences, with the regions of greatest diversity localized to the $5^{\prime}$ region of the gene, which encodes the signal sequence and amino-terminus of the secreted toxin (allele types s1a, s1b, s1c, or s2), an intermediate region (allele types i1 or i2), and a mid-region (allele types $\mathrm{m} 1$ or $\mathrm{m} 2$ ). Strains containing type $\mathrm{s} 1, \mathrm{i} 1$, and $\mathrm{m} 1$ alleles are strongly associated with gastric cancer [18], and in 2 recent studies, vacA s1 and i1 genotypes were determined to be better markers of intestinal metaplasia or gastric cancer than cagA genotypes $[19,20]$.

\section{Host Factors and Gastric Cancer}

Several studies have utilized high-level genetic analyses to identify host factors linked to $H$. pylori infection and gastric cancer. A recent GWAS study linked poly- 
morphisms within a TLR-encoding locus with the presence of $H$. pylori infection, although the specific relationship to gastric cancer was not determined [21]. Another group utilized MLST and SNP analysis to assess $H$. pylori and human genetic variation, respectively, in 2 unique Colombian populations with disparate risks for gastric cancer in order to assess co-evolutionary relationships within the context of pathogenic outcomes [22]. Specific interactions between microbial and human genetic ancestries clearly predicted disease risk, and all persons who fell within the lowest decile of African host ancestry content but who were infected with an $H$. pylori strain containing $>19.8 \%$ African ancestry, harbored a premalignant lesion. Thus, interactions between host and pathogen ancestries completely accounted for differences in the severity of gastric injury in these populations, suggesting that neither human nor $H$. pylori genetic variation confers disease susceptibility in isolation, but only within the context of a genetic mismatch.

Specific proinflammatory cytokine polymorphisms can greatly increase the risk of gastric cancer among $H$. pylori-infected persons $[23,24]$. In fact, odds ratio estimates for distal gastric cancer conferred by IL-1, IL-10, or TNF-alpha genetic polymorphisms are further amplified in persons infected with $\mathrm{cag}^{+}$strains when compared to the total $H$. pylori-infected population [25]. Persons infected with $H$. pylori isolates that possess type $\mathrm{s} 1 / \mathrm{m} 1$ $v a c A$ alleles are more likely to develop hypochlorhydria, a phenotype linked to high-expression alleles of IL- $1 \beta$ and gastric cancer. The combination of high-risk host genotypes and cancer-associated $v a c A$ alleles or cag genotype similarly increases the risk for gastric cancer markedly, up to 87-fold over baseline [26]. Thus, evaluating human genetic variation in conjunction with genetic analyses of infecting $H$. pylori strains can identify colonized persons who harbor the highest risk for gastric cancer and who may be optimal candidates for antimicrobial intervention.

Another promising area for gastric cancer research is defining the specific interactions that occur between $H$. pylori and stem cells. Stem cells are critical for regulating the self-renewing gastric epithelium and maintaining homeostasis, and evidence from mouse models and human tissue has indicated that $H$. pylori can interact with stem-cell populations [27]. In vivo lineage tracing of the gastric epithelium has demonstrated that Lgr5 (leucinerich repeat-containing $G$ protein-coupled receptor 5) positive cells are self-renewing and multipotent stem cells are capable of generating an entire antral gastric gland [28]. In the human stomach, $H$. pylori infection in pa- tients with gastric cancer leads to an increased population of Lgr5-positive epithelial cells in the antrum compared to uninfected persons with cancer [29]. Furthermore, in H. pylori-infected persons with cancer, Lgr5-positive cells are more susceptible to DNA damage than Lgr5-negative cells [29]. A recent novel study using 3D-confocal microscopy has demonstrated that $H$. pylori can specifically interact with $\mathrm{Lgr}^{+}$progenitor and stem cells, leading to their functional activation [27].

Leucine-rich repeats and immunoglobulin-like domains 1 (Lrig1) is a transmembrane protein that marks a distinct population of quiescent stem cells and functions as a tumor suppressor [30]. Lrig1 is expressed in the gastric epithelium, and expression of Lrig1 is increased in the gastric epithelium of $H$. pylori-infected vs. uninfected mice suggesting that infection with $H$. pylori increases this stem cell population as well [31].

Bone marrow derived cells (BMDCs) are a heterogeneous population of cells with the ability to differentiate into cells of diverse lineages. Studies in mice infected with Helicobacter have demonstrated that BMDCs home to and engraft in sites of chronic gastric inflammation, and repopulate the endogenous tissue stem cells [32]. Within an inflamed stomach, BMDCs degenerate into adenocarcinoma, suggesting that gastric epithelial carcinomas can originate from marrow-derived sources [32].

\section{Dietary Risk Factors}

The risk of gastric cancer is not only influenced by $H$. pylori strain-specific constituents and host genetics, but also by environmental factors such as diet. Diets that are rich in salted, pickled, smoked or poorly preserved foods, those with high meat content, and those with low fruit and vegetable content are most commonly associated with an increased risk for developing gastric cancer [33]. Within the context of $H$. pylori infection, high dietary salt intake and low iron levels are most highly associated with increased gastric cancer risk.

High dietary salt intake is associated with increased gastric cancer risk and has been reported in numerous studies [33], and $H$. pylori infection in combination with a high salt diet further increases cancer risk. In Mongolian gerbils, the combination of $H$. pylori infection and a high salt diet exerts synergistic effects on the development of premalignant lesions or gastric cancer [34, 35]. The mechanisms by which salt increases the risk for developing gastric cancer in humans are incompletely understood; however, recent data indicate that salt may modu- 
late virulence gene expression in $H$. pylori. Expression of cagA is significantly upregulated when certain strains of $H$. pylori are cultured in high salt concentrations [36], and salt-responsive strains more frequently harbor 2 copies of a $5^{\prime}$-TAATGA motif located within the cagA promoter [37].

In addition to salt, host iron levels have also been found to modulate the virulence potential of $H$. pylori, and iron deficiency is associated with an increased risk for gastric cancer. Long-term colonization with $H$. pylori can further exacerbate iron deficiency through the development of gastric atrophy, which leads to decreased acid secretion, reduced ascorbic acid levels and decreased iron absorption [38]. Our group has demonstrated that iron deficiency in $H$. pylori-infected persons accelerates the development of carcinogenesis by increasing the virulence potential of $H$. pylori [39]. We also performed mechanistic studies to determine the effects of dietary iron depletion on the development of $H$. pylori-induced carcinogenesis in gerbils [39]. H. pylori infection significantly increased the occurrence of dysplasia and gastric adenocarcinoma in iron-depleted gerbils compared to iron-replete gerbils [39], but these effects were present only after infection with CagA-positive H. pylori. To investigate the molecular mechanisms underlying these changes, the proteomes of $H$. pylori strains cultured from gerbils fed on an iron-depleted diet or on an iron-replete diet were compared. Proteins involved in function of the cag TFSS were differentially regulated when comparing H. pylori strains isolated from iron-depleted vs. iron-replete gerbils [39] and levels of phosphorylated CagA (reflecting translocated CagA), the number of cag T4SS pili, and induction of pro-inflammatory cytokines were significantly higher following co-culture with strains isolated from iron-depleted gerbils compared with strains isolated from iron-replete gerbils [39]. Collectively these data demonstrate that dietary iron depletion significantly increases the severity of gastric inflammation and accelerates the development of $H$. pylori-induced disease via augmentation of the cag secretion system.

\section{Treatment Recommendations for H. pylori}

The goal of anti-H. pylori therapy is to eliminate the organism from the stomach and successful eradication is defined as a negative test for the bacterium $\geq 4$ weeks after completion of therapy. Treatment regimens should be straightforward, well tolerated, and cost-effective. There are several different options for treating $H$. pylori infec-
Table 1. H. pylori resistance rates in Europe and the United States

\begin{tabular}{lll}
\hline Antibiotic & \multicolumn{2}{l}{ H. pylori resistance, \% } \\
\cline { 2 - 3 } & Europe $^{1}$ & United States $^{2}$ \\
\hline Clarithromycin & 17.5 & 17.8 \\
Levofloxacin & 14.1 & 31.9 \\
Metronidazole & 34.9 & 21.5 \\
\hline
\end{tabular}

${ }^{1}$ Resistance determined as reported in [47] in Europe.

${ }^{2}$ Resistance determined as reported in [48] in the United States.

tions, and selection of a particular therapy is dependent on many factors, including drug availability, antimicrobial resistance patterns of $H$. pylori strains, and cost. Two first-line therapies have been currently endorsed by the American College of Gastroenterology: triple therapy using a proton pump inhibitor (PPI) and 2 antibiotics or bismuth-containing quadruple therapy [40]. Triple therapy consists of a PPI plus clarithromycin $(500 \mathrm{mg})$ and either amoxicillin $(1 \mathrm{~g})$ or metronidazole $(500 \mathrm{mg})$, each ingested twice daily. Bismuth-based quadruple therapy consists of a PPI dosed twice daily plus bismuth, metronidazole, and tetracycline for 10-14 days. However, these therapies fail to eradicate $H$. pylori in up to $20-25 \%$ of patients, likely due to an increased global prevalence of antibiotic-resistant $H$. pylori strains (table 1) [41].

Sequential therapy in its original formulation consists of a proton-pump inhibitor daily plus amoxicillin $1 \mathrm{~g}$ twice a day for 5 days, followed by PPI therapy, clarithromycin $500 \mathrm{mg}$, and tinidazole $500 \mathrm{mg}$, each twice a day, for an additional 5 days. In a pooled analysis of 22 trials evaluating 2,388 patients, collective eradication rates were 91.3 and $93.7 \%$ (intention to treat and per protocol, respectively) [41]. An important caveat is the importance of the nitroimidazole used in this regimen. In patients receiving tinidazole (currently unavailable in the United States), eradication rates were $97.4 \%$ compared to $84.1 \%$ when metronidazole was substituted in the regimen, which may reflect the longer half-life of tinidazole [41]. Sequential therapy has been directly compared to standard triple therapy in several randomized trials and has achieved higher eradication rates with no difference in side effect profiles. Another advantage of sequential therapy is its ability to achieve high eradication rates for clarithromycin-resistant $H$. pylori strains and levofloxacin can be successfully incorporated into sequential therapy (levofloxacin replacing clarithromycin) [42]. However, geographic locale may influence eradication rates. A recent study in Latin America demonstrated that sequential 
Fig. 2. Anti-microbial therapies recommended for $H$. pylori eradication. * Or recent use of clarithromycin.

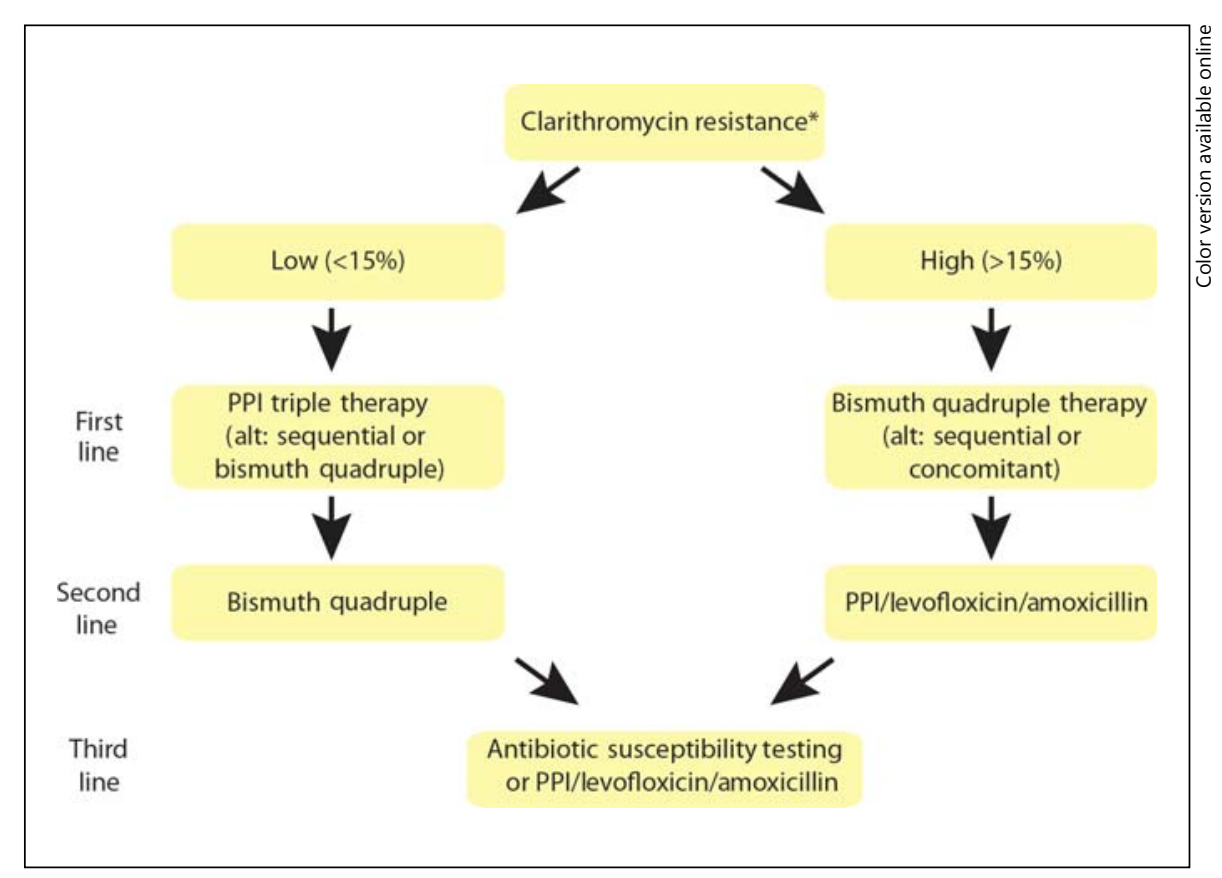

therapy was not superior to standard triple therapy, although metronidazole was used instead of tinidazole and antibiotic susceptibility patterns of infecting strains were not analyzed [43]. This study has raised questions regarding the use of sequential therapy as a first-line therapy for H. pylori eradication in the United States. Other concerns include the fact that the efficacy of sequential therapy may be reduced when metronidazole is used in place of tinidazole, and that sequential therapy contains amoxicillin as a major constituent, which limits its use in patients allergic to penicillin.

Another potential alternative to currently recommended first-line therapies is concomitant therapy, which combines a PPI with clarithromycin, metronidazole, and amoxicillin [44]. Although eradication rates using concomitant therapy have been reported to exceed $90 \%$, randomized trials evaluating this regimen have shown it to be less effective [43].

The most recent Maastricht IV/Florence Consensus Conference recommended the following strategy for treatment of $H$. pylori [45]. In areas with low rates of H. pylori clarithromycin resistance $(<15 \%)$, PPI-clarithromycin-containing triple regimens are recommended as first-line treatment; however, bismuth-containing quadruple therapy is an alternative (fig. 2). In areas of high clarithromycin resistance, bismuth-containing quadruple regimens are recommended as first-line empirical treatment. If this regimen is not available, sequential ther- apy or non-bismuth quadruple therapies such as concomitant therapy (PPI with clarithromycin, metronidazole, and amoxicillin) are recommended. Since local antibiotic resistance rates may not always be readily available, patients with recent or repeated exposure to clarithromycin should be assumed to harbor a resistant H. pylori strain (fig. 2).

In patients that fail eradication with a PPI-clarithromycin containing regimen, either bismuth-containing quadruple therapy or levofloxacin-containing triple therapies (PPI, levofloxacin, amoxicillin) are recommended (fig. 2). Levofloxacin-containing triple therapy is also recommended as a second-line therapy if bismuth-quadruple or non-bismuth quadruple therapies fail as first-line treatments. A meta-analysis that included 4 randomized trials of levofloxacin as a component of triple therapy reported higher eradication rates compared with a 7-day course of bismuth-based quadruple therapy, as well as fewer side effects [46]. Resistance to levofloxacin is a major limiting factor with resistance rates exceeding $16 \%$ in East Asia, Canada, certain regions of Europe, and the United States $[47,48]$. After failure of second-line therapies, treatment should be guided by antimicrobial susceptibility testing if possible. Any of the above regimens may be considered for second-line eradication, depending on the first-line therapy that was utilized [45]. One component of salvage regimens is rifabutin, an antibiotic used to treat mycobacterial infections. Eradication rates are typically inferior 
compared to regimens that employ levofloxacin and side effects can be severe, including myelosuppression.

Eradication rates in clinical practice are frequently $<90 \%$, primarily due to differences in patient populations, genetic diversity of infecting $H$. pylori isolates, and antibiotic resistance patterns. It is therefore recommended that urea breath testing or stool antigen tests be performed post intervention to confirm successful cure. Follow-up testing should be performed at least 4 weeks after the completion of therapy.

\section{Conclusions}

Gastric cancer leads to a high number of cancer-related deaths and understanding the risk factors for this disease is of utmost importance in identifying individuals who are most likely to develop malignancy. The risk of developing gastric cancer is dependent on numerous factors including $H$. pylori strain-specific virulence factors, the host genotype, and environmental factors such as diet. Interactions among these factors affect the outcome of long-term colonization of $H$. pylori; therefore, it is important to utilize results from mechanistic studies to identify persons who are most at risk of developing gastric cancer.

\section{Acknowledgments}

Grant support: NIH CA-116087, DK-58404, DK-58587, and CA-77955.

\section{Disclosure Statement}

The author has no conflicts of interest.

\section{References}

1 de Martel C, Ferlay J, Franceschi S, Vignat J, Bray F, Forman D, Plummer M: Global burden of cancers attributable to infections in 2008: a review and synthetic analysis. Lancet Oncol 2012;13:607-615.

2 Correa P: Human gastric carcinogenesis: a multistep and multifactorial process - first American Cancer Society award lecture on cancer epidemiology and prevention. Cancer Res 1992;52:6735-6740.

3 Polk DB, Peek RM Jr: Helicobacter pylori: gastric cancer and beyond. Nat Rev Cancer 2010; 10:403-414.

-4 Cristescu R, Lee J, Nebozhyn M, Kim KM, Ting JC, Wong SS, Liu J, Yue YG, Wang J, Yu K, Ye XS, Do IG, Liu S, Gong L, Fu J, Jin JG, Choi MG, Sohn TS, Lee JH, Bae JM, Kim ST, Park SH, Sohn I, Jung SH, Tan P, Chen R, Hardwick J, Kang WK, Ayers M, Hongyue D, Reinhard C, Loboda A, Kim S, Aggarwal A: Molecular analysis of gastric cancer identifies subtypes associated with distinct clinical outcomes. Nat Med 2015;21:449-456.

5 Salama N, Guillemin K, McDaniel TK, Sherlock G, Tompkins L, Falkow S: A whole-genome microarray reveals genetic diversity among Helicobacter pylori strains. Proc Natl Acad Sci U S A 2000;97:14668-14673.

-6 Censini S, Lange C, Xiang Z, Crabtree JE, Ghiara $\mathrm{P}$, Borodovsky M, Rappuoli R, Covacci A: Cag, a pathogenicity island of Helicobacter pylori, encodes type I-specific and disease-associated virulence factors. Proc Natl Acad Sci U S A 1996;93:14648-14653.

-7 Crabtree JE, Wyatt JI, Sobala GM, Miller G, Tompkins DS, Primrose JN, Morgan AG: Systemic and mucosal humoral responses to $\mathrm{He}$ - licobacter pylori in gastric cancer. Gut 1993; 34:1339-1343.

8 Odenbreit S, Püls J, Sedlmaier B, Gerland E, Fischer W, Haas R: Translocation of Helicobacter pylori CagA into gastric epithelial cells by type IV secretion. Science 2000;287:14971500.

-9 Backert S, Ziska E, Brinkmann V, ZimnyArndt U, Fauconnier A, Jungblut PR, Naumann M, Meyer TF: Translocation of the $\mathrm{He}$ licobacter pylori CagA protein in gastric epithelial cells by a type IV secretion apparatus. Cell Microbiol 2000;2:155-164.

10 Mueller D, Tegtmeyer N, Brandt S, Yamaoka Y, De Poire E, Sgouras D, Wessler S, Torres J, Smolka A, Backert S: C-Src and c-Abl kinases control hierarchic phosphorylation and function of the CagA effector protein in Western and East Asian Helicobacter pylori strains. J Clin Invest 2012;122:1553-1566.

11 Amieva MR, Vogelmann R, Covacci A, Tompkins LS, Nelson WJ, Falkow S: Disruption of the epithelial apical-junctional complex by Helicobacter pylori CagA. Science 2003;300:1430-1434.

12 Franco AT, Israel DA, Washington MK, Krishna U, Fox JG, Rogers AB, Neish AS, Collier-Hyams L, Perez-Perez GI, Hatakeyama M, Whitehead R, Gaus K, O'Brien DP, RomeroGallo J, Peek RM Jr: Activation of beta-catenin by carcinogenic Helicobacter pylori. Proc Natl Acad Sci U S A 2005;102:10646-10651.

13 Murata-Kamiya N, Kurashima Y, Teishikata Y, Yamahashi Y, Saito Y, Higashi H, Aburatani $\mathrm{H}$, Akiyama T, Peek RM Jr, Azuma T, Hatakeyama M: Helicobacter pylori CagA interacts with E-cadherin and deregulates the beta-catenin signal that promotes intestinal transdifferentiation in gastric epithelial cells. Oncogene 2007;26:4617-4626.

14 Saadat I, Higashi H, Obuse C, Umeda M, Murata-Kamiya N, Saito $\mathrm{Y}, \mathrm{Lu} \mathrm{H}$, Ohnishi N, Azuma T, Suzuki A, Ohno S, Hatakeyama M: Helicobacter pylori CagA targets PAR1/ MARK kinase to disrupt epithelial cell polarity. Nature 2007;447:330-333.

15 Viala J, Chaput C, Boneca IG, Cardona A, Girardin SE, Moran AP, Athman R, Mémet S, Huerre MR, Coyle AJ, DiStefano PS, Sansonetti PJ, Labigne A, Bertin J, Philpott DJ, Ferrero RL: Nod1 responds to peptidoglycan delivered by the Helicobacter pylori cag pathogenicity island. Nat Immunol 2004;5:1166-1174.

-16 Suarez G, Romero-Gallo J, Piazuelo MB, Wang G, Maier RJ, Forsberg LS, Azadi P, Gomez MA, Correa P, Peek RM Jr: Modification of Helicobacter pylori peptidoglycan enhances Nod1 activation and promotes cancer of the stomach. Cancer Res 2015;75:1749-1759.

-17 Cover TL, Blanke SR: Helicobacter pylori VacA, a paradigm for toxin multifunctionality. Nat Rev Microbiol 2005;3:320-332.

18 Rhead JL, Letley DP, Mohammadi M, Hussein N, Mohagheghi MA, Eshagh Hosseini M, Atherton JC: A new Helicobacter pylori vacuolating cytotoxin determinant, the intermediate region, is associated with gastric cancer. Gastroenterology 2007;133:926-936.

19 Memon AA, Hussein NR, Miendje Deyi VY, Burette A, Atherton JC: Vacuolating cytotoxin genotypes are strong markers of gastric cancer and duodenal ulcer-associated Helicobacter pylori strains: a matched case-control study. J Clin Microbiol 2014;52:2984-2989. 
20 Winter JA, Letley DP, Cook KW, Rhead JL, Zaitoun AA, Ingram RJ, Amilon KR, Croxall NJ, Kaye PV, Robinson K, Atherton JC: A role for the vacuolating cytotoxin, $\mathrm{VacA}$, in colonization and Helicobacter pylori-induced metaplasia in the stomach. J Infect Dis 2014; 210:954-963.

-21 Mayerle J, den Hoed CM, Schurmann C, Stolk L, Homuth G, Peters MJ, Capelle LG, Zimmermann K, Rivadeneira F, Gruska S, Völzke H, de Vries AC, Völker U, Teumer A, van Meurs JB, Steinmetz I, Nauck M, Ernst F, Weiss FU, Hofman A, Zenker M, Kroemer HK, Prokisch H, Uitterlinden AG, Lerch MM, Kuipers EJ: Identification of genetic loci associated with Helicobacter pylori serologic status. JAMA 2013;309:1912-1920.

-22 Kodaman N, Pazos A, Schneider BG, Piazuelo MB, Mera R, Sobota RS, Sicinschi LA, Shaffer CL, Romero-Gallo J, de Sablet T, Harder RH, Bravo LE, Peek RM Jr, Wilson KT, Cover TL, Williams SM, Correa P: Human and Helicobacter pylori coevolution shapes the risk of gastric disease. Proc Natl Acad Sci U S A 2014; 111:1455-1460.

23 El-Omar EM, Carrington M, Chow WH, McColl KE, Bream JH, Young HA, Herrera J, Lissowska J, Yuan CC, Rothman N, Lanyon G, Martin M, Fraumeni JF Jr, Rabkin CS: Interleukin-1 polymorphisms associated with increased risk of gastric cancer. Nature 2000; 404:398-402.

24 Amieva MR, El-Omar EM: Host-bacterial interactions in Helicobacter pylori infection. Gastroenterology 2008;134:306-323.

-25 El-Omar EM, Rabkin CS, Gammon MD, Vaughan TL, Risch HA, Schoenberg JB, Stanford JL, Mayne ST, Goedert J, Blot WJ, Fraumeni JF Jr, Chow WH: Increased risk of noncardia gastric cancer associated with proinflammatory cytokine gene polymorphisms. Gastroenterology 2003;124:1193-1201.

-26 Figueiredo C, Machado JC, Pharoah P, Seruca R, Sousa S, Carvalho R, Capelinha AF, Quint W, Caldas C, van Doorn LJ, Carneiro F, Sobrinho-Simões M: Helicobacter pylori and interleukin 1 genotyping: an opportunity to identify high-risk individuals for gastric carcinoma. J Natl Cancer Inst 2002;94:1680-1687.

-27 Sigal M, Rothenberg ME, Logan CY, Lee JY, Honaker RW, Cooper RL, Passarelli B, Camorlinga M, Bouley DM, Alvarez G, Nusse R, Torres J, Amieva MR: Helicobacter pylori activates and expands Lgr5(+) stem cells through direct colonization of the gastric glands. Gastroenterology 2015;148:13921404.e21.

28 Barker N, Huch M, Kujala P, van de Wetering M, Snippert HJ, van Es JH, Sato T, Stange DE, Begthel H, van den Born M, Danenberg E, van den Brink S, Korving J, Abo A, Peters PJ, Wright N, Poulsom R, Clevers H: Lgr5(+ve) stem cells drive self-renewal in the stomach and build long-lived gastric units in vitro. Cell Stem Cell 2010;6:25-36.

29 Uehara T, Ma D, Yao Y, Lynch JP, Morales K, Ziober A, Feldman M, Ota H, Sepulveda AR: $H$. pylori infection is associated with DNA damage of Lgr5-positive epithelial stem cells in the stomach of patients with gastric cancer. Dig Dis Sci 2013;58:140-149.

30 Powell AE, Wang Y, Li Y, Poulin EJ, Means AL, Washington MK, Higginbotham JN, Juchheim A, Prasad N, Levy SE, Guo Y, Shyr Y, Aronow BJ, Haigis KM, Franklin JL, Coffey $\mathrm{RJ}$ : The pan-ErbB negative regulator Lrig1 is an intestinal stem cell marker that functions as a tumor suppressor. Cell 2012;149:146-158.

31 Noto JM, Khizanishvili T, Chaturvedi R, Piazuelo MB, Romero-Gallo J, Delgado AG, Khurana SS, Sierra JC, Krishna US, Suarez G, Powell AE, Goldenring JR, Coffey RJ, Yang VW, Correa P, Mills JC, Wilson KT, Peek RM Jr: Helicobacter pylori promotes the expression of Krüppel-like factor 5, a mediator of carcinogenesis, in vitro and in vivo. PLoS One 2013;8:e54344.

- 32 Houghton J, Stoicov C, Nomura S, Rogers AB, Carlson J, Li H, Cai X, Fox JG, Goldenring JR, Wang TC: Gastric cancer originating from bone marrow-derived cells. Science 2004;306: 1568-1571.

33 Cover TL, Peek RM Jr: Diet, microbial virulence, and Helicobacter pylori-induced gastric cancer. Gut Microbes 2013;4:482-493.

34 Kato S, Tsukamoto T, Mizoshita T, Tanaka H, Kumagai T, Ota H, Katsuyama T, Asaka M, Tatematsu M: High salt diets dose-dependently promote gastric chemical carcinogenesis in Helicobacter pylori-infected Mongolian gerbils associated with a shift in mucin production from glandular to surface mucous cells. Int J Cancer 2006;119:1558-1566.

35 Gaddy JA, Radin JN, Loh JT, Zhang F, Washington MK, Peek RM Jr, Algood HM, Cover TL: High dietary salt intake exacerbates Helicobacter pylori-induced gastric carcinogenesis. Infect Immun 2013;81:2258-2267.

36 Loh JT, Torres VJ, Cover TL: Regulation of Helicobacter pylori CagA expression in response to salt. Cancer Res 2007;67:47094715.

37 Loh JT, Friedman DB, Piazuelo MB, Bravo LE, Wilson KT, Peek RM Jr, Correa P, Cover TL: Analysis of Helicobacter pylori cagA promoter elements required for salt-induced upregulation of CagA expression. Infect Immun 2012;80:3094-3106.

38 Yip R, Limburg PJ, Ahlquist DA, Carpenter HA, O'Neill A, Kruse D, Stitham S, Gold BD, Gunter EW, Looker AC, Parkinson AJ, Nobmann ED, Petersen KM, Ellefson M, Schwartz S: Pervasive occult gastrointestinal bleeding in an Alaska native population with prevalent iron deficiency. Role of Helicobacter pylori gastritis. JAMA 1997;277:1135-1139.
39 Noto JM, Gaddy JA, Lee JY, Piazuelo MB, Friedman DB, Colvin DC, Romero-Gallo J, Suarez G, Loh J, Slaughter JC, Tan S, Morgan DR, Wilson KT, Bravo LE, Correa P, Cover TL, Amieva MR, Peek RM Jr: Iron deficiency accelerates Helicobacter pylori-induced carcinogenesis in rodents and humans. J Clin Invest 2013;123:479-492.

40 Chey WD, Wong BC; Practice Parameters Committee of the American College of Gastroenterology: American college of gastroenterology guideline on the management of $\mathrm{He}$ licobacter pylori infection. Am J Gastroenterol 2007;102:1808-1825.

41 Vaira D, Zullo A, Hassan C, Fiorini G, Vakil $\mathrm{N}$ : Sequential therapy for Helicobacter pylori eradication: the time is now! Therap Adv Gastroenterol 2009;2:317-322.

42 Romano M, Cuomo A, Gravina AG, Miranda A, Iovene MR, Tiso A, Sica M, Rocco A, Salerno R, Marmo R, Federico A, Nardone G: Empirical levofloxacin-containing versus clarithromycin-containing sequential therapy for Helicobacter pylori eradication: a randomised trial. Gut 2010;59:1465-1470.

43 Greenberg ER, Anderson GL, Morgan DR, Torres J, Chey WD, Bravo LE, Dominguez RL, Ferreccio C, Herrero R, Lazcano-Ponce EC, Meza-Montenegro MM, Peña R, Peña EM, Salazar-Martínez E, Correa P, Martínez ME, Valdivieso M, Goodman GE, Crowley JJ, Baker LH: 14-day triple, 5-day concomitant, and 10-day sequential therapies for $\mathrm{He}$ licobacter pylori infection in seven Latin American sites: a randomised trial. Lancet 2011;378:507-514.

44 Vakil N, Megraud F: Eradication therapy for Helicobacter pylori. Gastroenterology 2007; 133:985-1001.

45 Malfertheiner P, Megraud F, O’Morain CA, Atherton J, Axon AT, Bazzoli F, Gensini GF, Gisbert JP, Graham DY, Rokkas T, El-Omar EM, Kuipers EJ; European Helicobacter Study Group: Management of Helicobacter pylori infection - the Maastricht IV/Florence consensus report. Gut 2012;61:646-664.

46 Saad RJ, Schoenfeld P, Kim HM, Chey WD: Levofloxacin-based triple therapy versus bismuth-based quadruple therapy for persistent Helicobacter pylori infection: a meta-analysis. Am J Gastroenterol 2006;101:488-496.

47 Megraud F, Coenen S, Versporten A, Kist M, Lopez-Brea M, Hirschl AM, Andersen LP, Goossens H, Glupczynski Y; Study Group Participants: Helicobacter pylori resistance to antibiotics in Europe and its relationship to antibiotic consumption. Gut 2013;62:3442.

48 Shiota S, Reddy R, Alsarraj A, El-Serag HB, Graham DY: Antibiotic resistance of Helicobacter pylori among male United States veterans. Clin Gastroenterol Hepatol 2015;13: 1616-1624. 